\title{
POLAR GRAPHS OF INITIAL MOTIONS AT AN EARTHQUAKE SOURCE
}

\author{
By Markus BÅTH
}

\begin{abstract}
A modified technique for fault-plane solutions is developed, using polar diagrams with the earthquake focus at the origin and with station azimuth and angle of incidence at the focus as coördinates. A figure is given illustrating the distribution of initial longitudinal motion in a perfectly general case for a plane fault source with rectilinear slip, together with all the special cases which can be derived from it. Formulas are given which combine all the quantities entering into the solution.
\end{abstract}

AN EFFECTIVE graphic representation of the pattern of initial longitudinal wave motions at a point source is given by a plot on a horizontal plane through the focus of the first motions in a polar diagram with station azimuth and angle of incidence at the source as coördinates. The focus $\mathrm{O}$ is placed at the origin. Each point shows the direction of the radial component (outward or compression, inward or dilatation) in the half space below the horizontal plane. A similar graph showing direction of radial motion for the upper half space can be constructed for observations from near stations or from $\mathrm{pP}$ at larger distances. Figure 1 shows the different distribution patterns of dilatations and compressions for plane fault sources with rectilinear slip. The following notation is used:

$\mathrm{FF}=$ the intersection between the fault plane and the horizontal plane through the focus $\mathrm{O}$

$\mathrm{MM}=$ the intersection between a plane perpendicular to the direction of slip and the horizontal plane through $\mathrm{O}$

$i_{F} \quad=$ the angle between the fault plane and the vertical

$i_{M}=$ the angle of the plane, perpendicular to the slip direction, with the vertical

(in figure 1 these angles are indicated by lines perpendicular to FF and MM respectively)

$\alpha \quad=$ the angle between FF and MM in the horizontal plane through $\mathrm{O}$

$\beta \quad=$ the angle in the fault plane between the dip and the slip.

For a given direction of FF only two of the four angles $i_{F}, i_{M}, \alpha, \beta$ are necessary to specify the solution. The geometry of the three-dimensional figure leads to the following relations:

$$
\begin{aligned}
& \cos \alpha=\tan i_{M} \cdot \tan i_{F} \\
& \cos \beta=\sin i_{M} / \cos i_{F}
\end{aligned}
$$

Note that

$$
\tan \beta=\text { strike component / dip component }
$$

The curves limiting compressional areas from dilatational have the following equation in polar coördinates $i_{L}, \gamma$ :

$$
\tan i_{L} \cdot \cos \gamma=\tan i_{F, M}
$$

Manuscript received for publication March 25, 1957. 


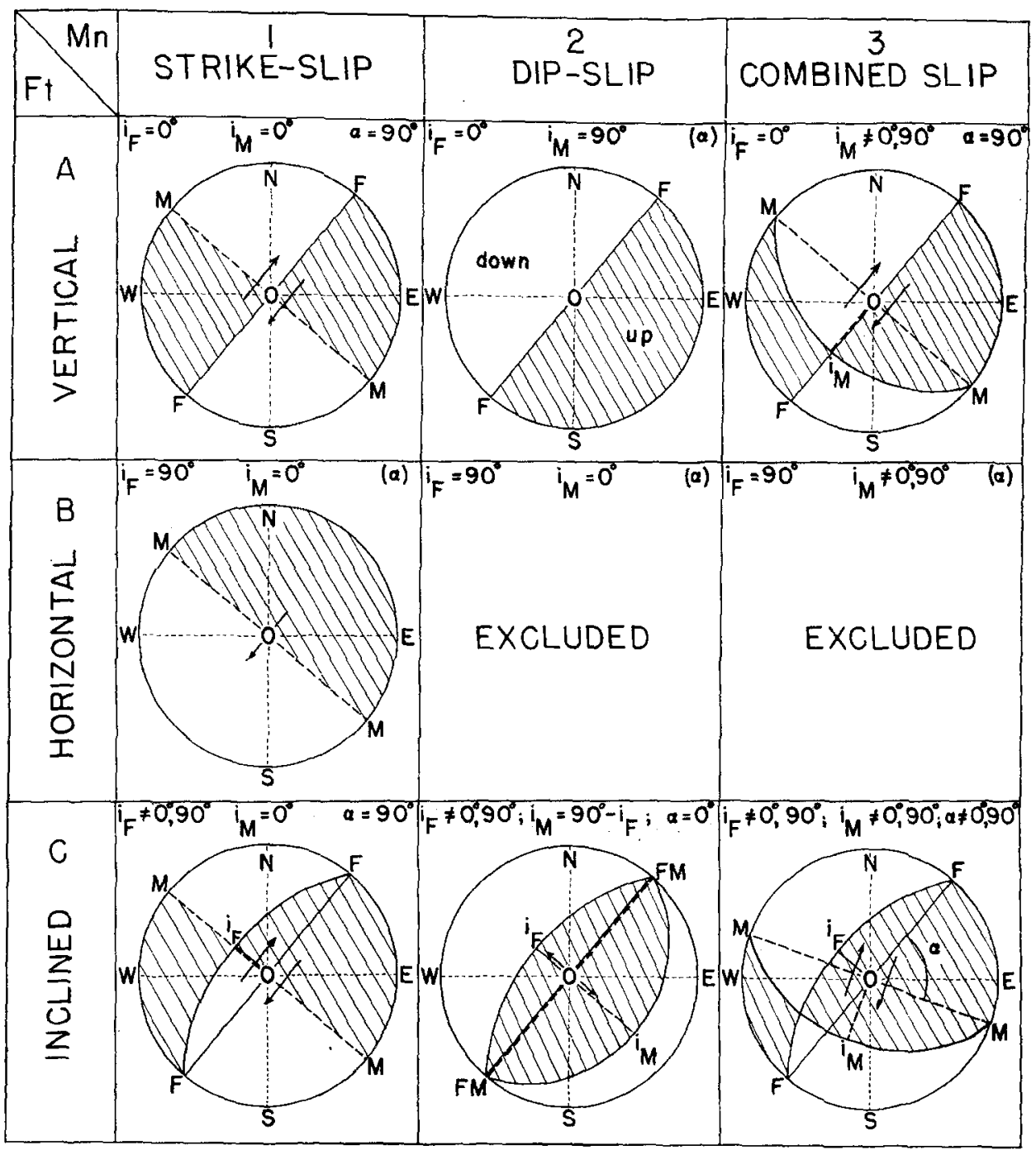

Fig. 1. Polar plots of the distribution of dilatations (dashed areas) and compressions with the focus $O$ at the origin and station azimuth and angle of incidence at $O$ as coördinates. Ft $=$ fault plane, $\mathrm{Mn}=$ motion or kind of $\operatorname{slip}(a)$ indicates an indeterminate value. 
where $i_{L}$ is the limit of $i$ in the azimuth $\gamma$, where $\gamma$ is measured from the perpendicular to FF and MM respectively. These curves are circular arcs with the following radius, expressed in degrees:

$$
r_{F, M}=\left[\left(90^{\circ}\right)^{2}+i_{F, M}^{2}\right] / 2 i_{F, M}
$$

All the special cases in figure 1 can be derived from the general case (3C) given in the same figure. Reversed directions of motion will naturally change every compression into dilatation, and vice versa. Graphs of this kind provide a clear and direct representation of the radial motion at the source responsible for the observed first motion at any given station.

My most sincere thanks are due to Professors H. Benioff, B. Gutenberg, and C. F. Richter for many valuable discussions.

Setsmological Laboratory,

Caltfornia Institute of Technologr,

Pasadena, California.

(Division of Geological Sciences, contribution no. 827.) 